\title{
The Interface Between Entrepreneurship as a Climate Change Mitigation Strategy and Improved Rural Household Food Security and Food Systems Sustainability in South Africa
}

\author{
Ndou Portia ${ }^{1}$, Bridget Taruvinga ${ }^{1}$, Igenicious N. Hlerema ${ }^{1}$, Christian P. du Plooy ${ }^{1} \&$ Sonja L. Venter ${ }^{1}$ \\ ${ }^{1}$ Agricultural Research Council, Vegetable and Ornamental Plants (ARC-VOP), South Africa \\ Correspondence: Portia Ndou, Agricultural Council-Vegetable and Ornamental Plants, Private Bag X293, \\ Pretoria 0001, South Africa. Tel: 27-128-088-000. E-mail: NdouP@arc.agric.za
}

Received: August 31, 2018

Accepted: April 4, 2019 Online Published: June 15, 2019

doi:10.5539/jas.v11n8p58

URL: https://doi.org/10.5539/jas.v11n8p58

\begin{abstract}
The worst and most direct impacts of climate change will fall disproportionately on livelihood systems and vulnerable populations that are already poor and food insecure. The highly vulnerable are communities dominated by farming, with limited livelihood diversification and adaptive capacity at household level. During the past three years, rural enterprises were established in six provinces of South Africa to increase access to food and to create income streams for farming communities in rural areas as part of the broader rural development strategy. This study sought to determine the impact of smallholder agricultural entrepreneurship through sweet potato and indigenous vegetable production on improved access to food, income generation and job creation. Return on Investment and Logistic regression analysis were used to analyse the data collected from 186 project beneficiaries. The results of the study indicated that enterprise development intervention impacted positively on household income, job creation and formal market access. The logistic regression model showed a significant relationship between productivity and access to formal markets $(\mathrm{P}<0.001)$, educational level $(\mathrm{P}<0.0001)$ and access to training $(\mathrm{P}<0.002)$ at the $1 \%$ significance level. Sustainable establishment of these enterprises must be ensured through infrastructure support, capacity building and adapting to changes in cultivation practices intended to cope with climate change.
\end{abstract}

Keywords: food security, climate change mitigation, enterprise development, sustainable, markets

\section{Introduction}

Global climate change is a critical potential challenge to the agricultural industry. Climate changes are expected to lead to increased crop productivity in some cooler temperate regions in the higher latitudes and altitudes, and a decline in per capita cultivated area and labour productivity in the warmer regions. Climate variability and change has been projected to severely compromise agricultural production and access to food in Africa (IPCC, 2007)-thus, extremely impact on livelihood systems and vulnerable populations that are already poor and food insecure. The problem of vulnerability of climate change impact is critical in light of an estimated 9\% (250 $\mathrm{kcal} / \mathrm{capita} /$ day) world food consumption increase by year 2030 (Bruinsma, 2003; Valin et al., 2010), in response to the population increase which is also estimated to double for low income countries such as those in Africa (Harsch, 2005). To accommodate this, cropland will need to increase by between 6 and 30\% by 2050 (Smith et al., 2010). Since land is a fixed asset, this increase in cropping land may not necessarily be feasible to access for producing food, to match the population growth. Therefore, production per unit area may need to increase.

It is however, postulated that farmer susceptibility to climate change will vary by region (Brown \& Funk, 2008). Several factors underpin the susceptibility of developing countries to the effects of climate change. These include low agricultural productivity (Brown \& Funk, 2008), widespread poverty, direct reliance primarily on climate-sensitive resources for income generation and survival (World Bank, 2010), heavy reliance (e.g., 70\% of the African population) on rain-fed agriculture for livelihoods (Shiferaw et al., 2014), limited coping capacity by the civil society, private sector and government (UNFCCC, 2007). Other factors include limited livelihood diversification and adaptive capacity at household level amidst heavy reliance on farming.

The most direct implications of climate change for food security of rural households are through its impacts on food production. Adaptation efforts are undermined by lack of proper infrastructure, limited human and financial 
means, along with weak institutional capacity (World Bank, 2010). There also is uncertainty about the local impacts of climate change as a barrier to action (NRC, 2004) and the constraints of adaptive behaviour associated with incomplete knowledge of disaster safety options (Murphy, 2004; Murphy et al., 2005). Figure 1 depicts the generic drivers of household food insecurity. Climate change is one factor amongst many, thus a holistic approach to addressing the problem of food insecurity is inevitable. In essence, since climate change acts through both the reduction of food production and restricted access to food, its impact cannot be solved in isolation from these key drivers. In fact, the former become the key routes through which the negative influences of climate change can be curbed.

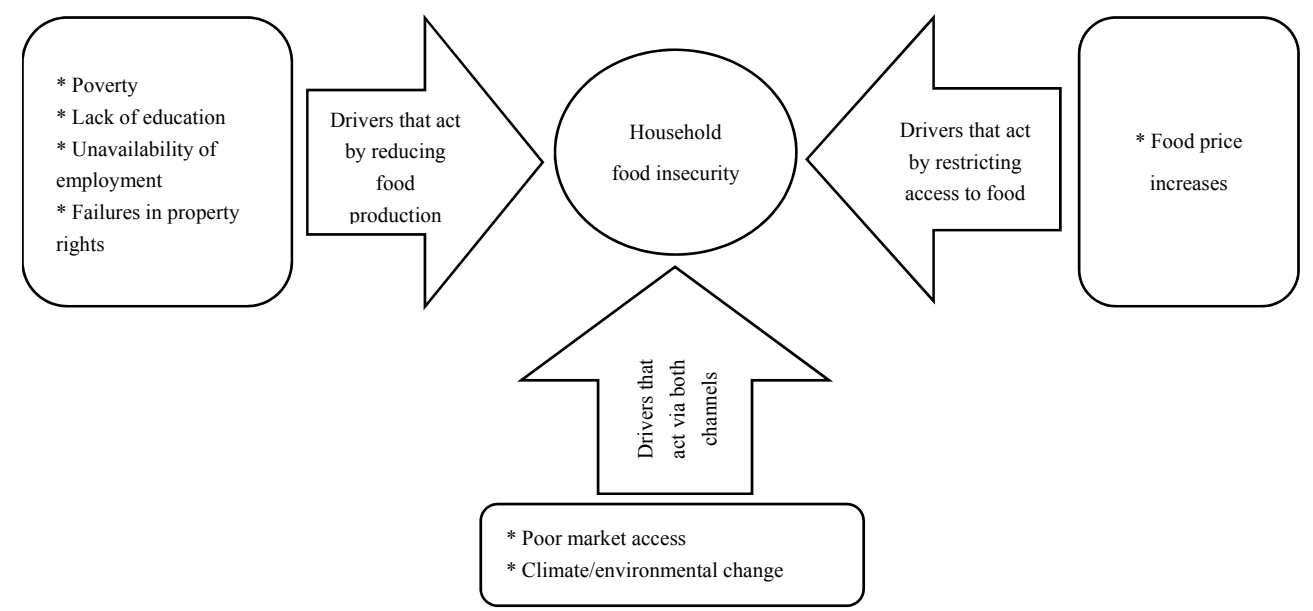

Figure 1. Main drivers of household food insecurity

Source: Scholes and Briggs (2004).

Amidst the ever-changing climatic conditions, the question can never be whether food systems and food security are affected, but rather how and in what ways they are affected and how key stakeholders should strategise the resilience of the agricultural industry as well as ensuring food security within efficient food systems. The need to understand climate change should lead to the development of techniques for adaptation and mitigation under different conditions. In fact, adaptation has been viewed as an important area of focus in the bid to fight the effects of climate change. Agricultural land use should be viewed in light of its contribution to increased food production. Resilient crops will remain unaffected by climate change (FAO, 2010).

This study draws its strength from the smallholder Enterprise Development Projects piloted in six provinces of South Africa since 2013. The enterprises were established among the smallholder communities of the six provinces namely Gauteng, Limpopo, North West, Eastern Cape, KwaZulu-Natal and Mpumalanga. The primary purpose of the programme was to promote commercial production for income generation purposes as well as job creation. The farmers that were chosen to benefit from the projects had to meet certain requirements, which included availability of at least 1 hectare of land for production purposes under the project, availability of water for irrigation and the farmer's interest in and passion for farming, especially as related to the crops that were supported by the projects. In addition, the farmers were chosen from Comprehensive Rural Development Programme (CRDP) sites, which are rural impoverished locations that depend mostly on natural resources for economic activities. The beneficiaries were supported with inputs including planting material, training on agronomic practices and business management skills, market surveys and linkages together with monitoring of the programme that stretched from pre-planting assessment to marketing of the produce. The study sought to identify the determinants of productivity within the smallholder sweet potato and African Leafy Vegetables (ALVs) enterprise beneficiaries. The promotion of the cultivation of sweet potatoes and ALVs was based on their inherent resilience to harsh climatic conditions. The study also made deductions of possible potential of the Enterprise Development Projects to mitigate climate change shocks among the smallholder farming community.

\section{Method}

A questionnaire was administered to 186 Enterprise Development Project beneficiaries. All the project beneficiaries participated in the survey as the population was small. The analysis of gathered data centred on 
identifying the determinants of success or productivity, as well as economic returns of the established enterprises, where the logistic regression model and Return on Investment analyses were used respectively. Productivity indicators were the yield as well as the profit generated. Due to the nature of the support given for the establishment of these enterprises, it was generally logical to use the same metrics to estimate the performance of the farmers.

\subsection{Logistic Regression Model}

The binary logistic regression model is specified as follows:

$$
Y=\alpha+\beta_{1} \chi_{1}+\beta_{2} \chi_{2}+\beta_{3} \chi_{3} \ldots+\beta_{k} \chi_{k}+\varepsilon
$$

Where,

$\alpha=$ the intercept; $Y=$ the dependant, explained response or predicted variable; $\chi_{1} \ldots \chi_{k}=$ are the independent, explanatory, control or predictor variables, or regressors; $\beta=$ the slope parameter; $\varepsilon=$ the unobserved error or disturbance term.

In binary logistic regression, the options taken by the dependent variable are usually coded as 0 or 1 , where the noteworthy possible outcome is usually coded as 1 and the contrary as 0 (Hill et al., 2001). In the current study the dependent variable is represented by increased productivity, therefore an increase in productivity takes the value of 1 , and none increase is coded as 0 . In order to determine increase in productivity, two indicators were used namely yield of produce and the profit generated through the enterprise. In order to capture the yield indicator, respondents were required to answer 5 questions related to the qualitative and quantitative aspects of the produce. For the profit generated indicator, respondents had to answer 7 questions that were related to income received, costs incurred in production, markets utilised for sales and duration of receiving payment. The responses to the 12 questions (yield and profit) were rated using a 5-point Likert scale, where 1 represented the lowest negative response (decrease/changed for the worst), 3 as neutral (no change) and 5 represented the highest positive response (increase/improvement). An average score per beneficiary from the 12 questions was then calculated in order to determine whether or not there was an increase in productivity. Enterprises with an average score of above 3 were regarded as succeeding because it meant that based on the 12 questions the farmers' overall productivity had improved. Enterprises with average scores of above 3, therefore took the value of 1 in the binary logistic regression.

Table 1 presents the variables utilised in the identification of determinants of productivity among the beneficiaries of the enterprise development projects.

Table 1. Description of variables utilised

\begin{tabular}{lll}
\hline Variable & Code & Description \\
\hline Education level of respondent & EDUC & Education level of respondent (primary, secondary, tertiary, illiterate) \\
Access to formal markets & FORMAL MKTS & Binary variable for farmer's penetration into formal markets (Yes/No) \\
Market size & MKTSIZE & Number of marketing channels available to the farmer \\
Access to technology & TECH & Dummy variable for use of technology, 1 = use \\
Access to markets in general & MKTACC & Dummy variable for access to any form of markets, 1= have access \\
Access to agricultural inputs & ACCINP & Dummy variable for access to agricultural inputs, $1=$ have access \\
Availability and use of irrigation facilities & IRRIG FACILITY & Dummy variable for availability and use of any form of irrigation system, \\
& & $1=$ have access and in use \\
Contact with extension officers & EXTCONT & Binary variable for farmer's contact to extension advice (Yes/No) \\
Access to extension training on farming & ACC TRAINING & Binary variable for farmer's receipt of training by extension agents (Yes/No) \\
Access to market information & MKTINFO & Binary variable for farmer's ability to access market information (Yes/No) \\
Experience in farming & EXPER & Number of years in farming \\
Access to financial credit & ACCFIN & Dummy variable, 1 if farmer has access to credit, or else, 0 \\
Availability of farm labourers & HUMCAP & Availability of farm labourers for farming activities \\
\hline
\end{tabular}

\subsection{Return on investment}

The Return on Investment (ROI) analysis was used as an ex-post evidence of the economic viability of the established enterprises. The formula is stated as:

$$
R O I=\left[\frac{G I-C I}{C I}\right] \times 100
$$


Where, $G I$ is the gain from investment and $C I$ is the cost of investment. The ROI can assume either a negative or positive value. For the investment to be financially viable, the ROI should be positive or else the investment will not be worthwhile.

\section{Results and Discussion}

The sweet potato and African Leafy Vegetables (ALV) projects generated an aggregate gross income of R $1,416,671.00$ and R 347,706.00 respectively in one season. Six hundred and thirty-seven (637) jobs (471 for sweet potato enterprises and 166 for ALVs respectively) were also created in the process. Table 2 shows the range of the Return On Investment for the established projects. All the beneficiary enterprises had a positive ROI, implying that it was profitable. Sweet potato vine nurseries performed the best compared to the Sweet potatoes growers and African Leafy Vegetables enterprises. The average ROI for the sweet potato vine nurseries was 2.20, implying that the majority had a ROI close to the highest level (2.43). The return on investment is highly likely to improve as the majority of these farmers were first time growers of the promoted crops.

Table 2. Return on Investment for the established projects

\begin{tabular}{llll}
\hline \multirow{2}{*}{ Project } & \multicolumn{3}{c}{ Return On Investment } \\
\cline { 2 - 4 } & Minimum & Highest & Average \\
\hline Sweet Potato Growers & 0.56 & 1.86 & 1.65 \\
Sweet Potato Vine Nurseries & 1.58 & 2.43 & 2.20 \\
African Leafy Vegetables & 0.52 & 1.10 & 0.88 \\
\hline
\end{tabular}

Table 3 presents only those variables that were found to be statistically significant at different levels of significance $(1 \%, 5 \%$ and $10 \%$ levels of significance). Productivity was significantly influenced by access to formal markets $(P<0.001)$, educational level $(P<0.0001)$, access to training $(P<0.002)$ and access to irrigation facility $(P<0.0001)$ (Table 2$)$. The results corroborates past research findings that found that education and training contribute to agricultural productivity (Pudasaini, 1983; Alene and Manyong, 2006). Training imparted technical and entrepreneurial skills necessary for all facets of enterprise development including production, management and harvesting of the crop. As stipulated by Smith (1976), "Consumption is the sole end purpose of all production: and the interest of the producer ought to be attended to only so far as it may be necessary to promoting that of the consumer". All the support given to the producers was intended to ensure good quality produce that will meet the benefits of both the producer and the consumer. In turn, linking the smallholder producers to formal markets created a conducive environment for the producer to participate in the mainstream value chain where they could fetch favourable returns for the produce. Access to market information $(\mathrm{P}<$ 0.0001), farmers' farming experience $(\mathrm{P}<0.0001)$ as well as access to finance were also key in influencing productivity.

Table 3. Determinants of productivity among the Enterprise Development Project farmers

\begin{tabular}{llll}
\hline Variable & Parameter Estimate & Standard Error & P-Value \\
\hline INTERCEPT & -13009 & 10501 & $<.0001$ \\
EDUC & 69627 & 1611.6 & $<.0001 * * *$ \\
FORMAL MKTS & 130.89 & 22.364 & $<.0001 * * *$ \\
MKTSIZE & 586.9 & 317.87 & $0.0699^{*}$ \\
TECH & 36.572 & 10.061 & $0.0006^{* * *}$ \\
MKTACC & 0.6190 & 0.2707 & $0.0222^{*}$ \\
ACCINP & 28.576 & 8.5010 & $0.0014^{* * *}$ \\
IRRIG FACILITY & 14648 & 1614.5 & $<.0001 * * *$ \\
EXTCONT & 11.38 & 6.530 & $0.0869^{*}$ \\
ACC TRAINING & 25649 & 6449.9 & $0.0023^{* * *}$ \\
MKTINFO & 13007 & 1946.1 & $<.0001 * * *$ \\
EXPER & 59628 & 10567 & $<.0001 * * *$ \\
ACCFIN & 201382 & 64717 & $0.0029 * *$ \\
HUMCAP & 10.91 & 6.3524 & $0.0915^{*}$ \\
\hline
\end{tabular}

Note. $\mathrm{N}=186$ : ${ }^{*}$ stands for $10 \%$ level of significance, ${ }^{* *}$ stands for $5 \%$ level of significance, ${ }^{* * *}$ stands for $1 \%$ level of significance, respectively. 


\section{Conclusion}

Based on the ROI for the established enterprises, this paper concludes that the commercial production of sweet potato and indigenous vegetables is an economically viable venture. The positive ROI indicates that the entrepreneur can cover all production costs from the total income of the enterprise. The enterprises are sustainable due to the implicit ability to improve, expand and to reinvest. The ability to produce more food manifested by the research results should be supported by setting processes in place to ensure more efficient and equitable use of the same. The promotion of the cultivation of more resilient crops is important in the light of climate change effects that are envisaged to negatively impact on agricultural production. On the same vein, climate change information must be availed in a form that fits the needs of decision-makers.

The projects yielded high economic returns for the established enterprises. In spite of their high resilience to harsh climate conditions, sweet potato and indigenous vegetables are highly nutritious and capable of contributing micronutrients such as iron and Vitamin A to diet. Thus, there were significant benefits for indirect beneficiaries of the project e.g. through employment creation and availability of and access to nutritious food (both economic \& physical).

\section{Recommendations}

The smallholder farming communities are inherently unable to sustain their agricultural activities at commercial levels without external support of various forms and kinds. A multifaceted approach is needed to ensure sustainable agricultural food production and food security. This study proposes several interlinked and interconnected interventions and strategies to enhance the performance and sustainability of the smallholder farmer production and market participation. Figure 2 sums up the interventions and strategies for sustainable smallholder entrepreneurship. The proposed intervention strategies will curb the main drivers of food insecurity, which mainly act by reducing food production and by restricting access to food as well as through a combination of both avenues of which poor access to markets and climate change or environmental change are key.

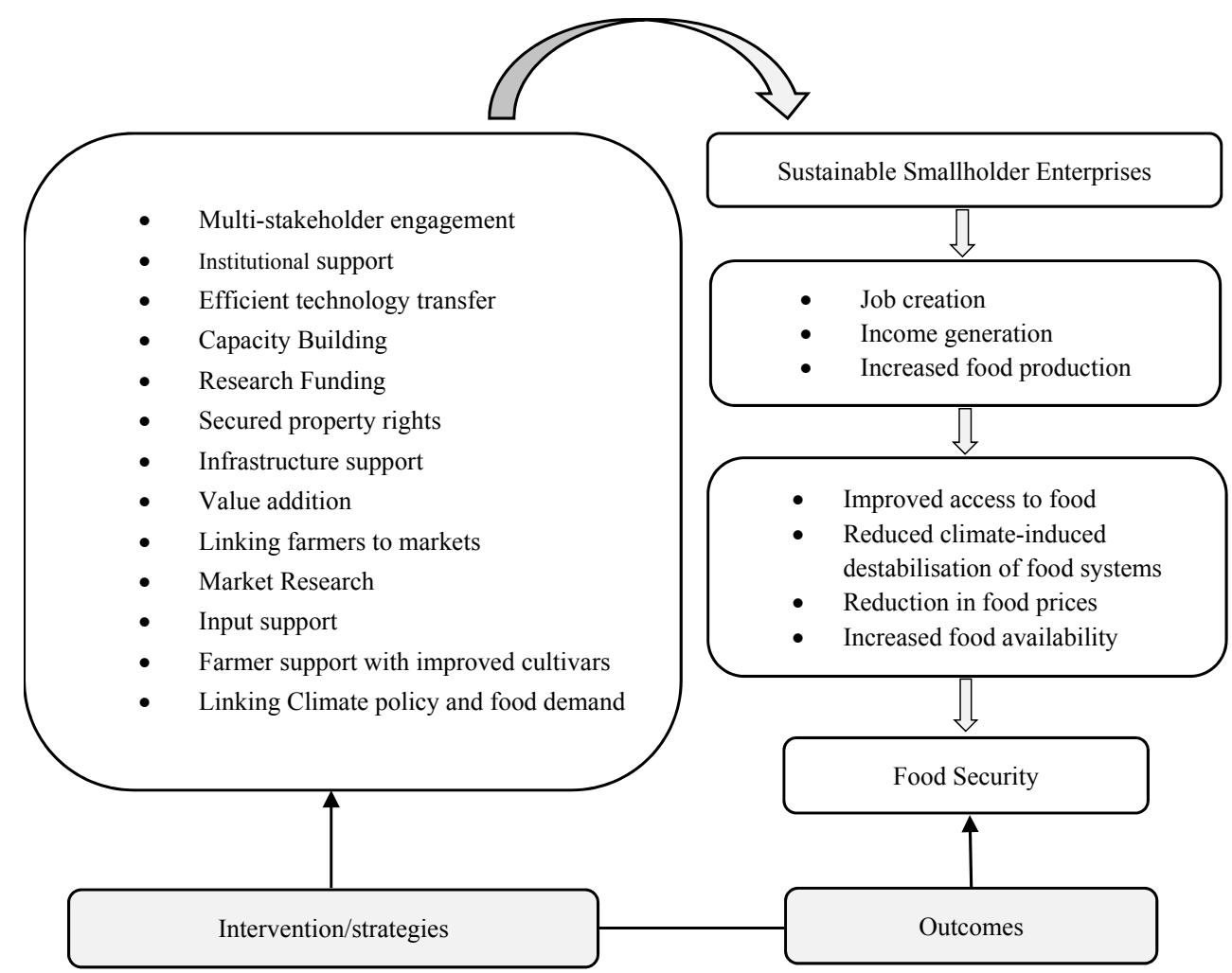

Figure 2. Interventions and strategies to enhance smallholder farmer production and market participation

There is need for engaging different stakeholders for advanced smallholder support. Several support structures also need to be put in place among which are infrastructure and input support, research which needs to cover the development of improved crop cultivars that can adapt easily to climate change and variations. Farmers need to 
be capacitated through training and efficient transfer of technology. To increase the returns to the primary producers, there is need to promote value addition at farm-gate which may entail agro-processing activities. Market research should be corroborated with linking the farmers to the identified high value markets. These interventions will enhance the sustainability of the established farming enterprises which in turn will result in food security for both participating producers and those benefiting through multiplier effects.

\section{References}

Alene, A. D., \& Manyong, V. M. (2006). The effects of education on agricultural productivity under traditional and improved technology in northern Nigeria: An endogenous switching regression analysis. Empirical Economic, 32, 141- 159. https://doi.org/10.1007/s00181-006-0076-3

Brown, E. M., \& Funk, C. C. (2008). Food security under climate change. Science, 319, 580-581. https://doi.org/10.1126/science. 1154102

Bruinsma, J. (2003). World agriculture: Towards 2015/2030: An FAO perspective. Earthscan/James \& James.

Food and Agricultural Organisation. (2010). Climate Change Implications for Food Security and Natural Resource Management in Africa. Twenty-sixth Regional Conference for Africa, Luanda, Angola.

Hill, R. C., Griffiths, W. E., \& Judge, G. G. (2001). Econometrics (2nd ed.). New York: John Wiley \& Sons Inc.

Harsch, E. (2005). Focusing aid on Africa's own priorities. Retrieved from http://www.un.org/africarenewal/ magazine/july-2005/focusing-aid-africa\%E2\%80\%99s-own-priorities

Intergovernmental Panel on Climate Change. (2007). Climate Change 2007: Impacts, Adaptation and Vulnerability. Working Group II Contribution to the Fourth Assessment Report of the Intergovernmental Panel on Climate Change. Cambridge, UK: Cambridge University Press. https://oi.org/10.1017/ CBO9780511546013

Murphy, B. (2004). Emergency Management and the August 14 th 2003 Blackout (p. 11). Institute for Catastrophic Loss Reduction, ICLR Research Paper Series No. 40, Toronto, Canada. Retrieved from http://www.iclr.org/ pdf/Emergency\%20Preparedness\%20and\%20the\%20blackout2.pdf

Murphy, B., McBean, G., Dolan, H., Falkiner, L., \& Kovacs. P. (2005). Enhancing local level emergency management: The influence of disaster experience and the role of household and neighbourhoods (p. 79). Institute for Catastrophic Loss Reduction, ICLR Research Paper Series No. 43, Toronto, Canada.

National Research Council. (2004). Thinking Strategically: The Appropriate use of Metrics for the Climate Change Science Program (p. 162). U.S. National Research Council-Committee on Metrics for Global Climate Change, Climate Research Committee, National Academy Press, Washington District of Columbia. Retrieved from http://books.nap.edu/catalog/11292.html

Pudasaini, S. P. (1983). The effects of Education in agriculture: Evidence from Nepal. American Journal of Agricultural Economics, 65(3), 509-515. https://doi.org/10.2307/1240499

Scholes, R. J., \& Biggs, R. (2004). Ecosystem services in Southern Africa: A regional assessment. Pretoria, South Africa: Council for Scientific and Industrial Research.

Shiferaw, B., Tesfaye, K., Kassie, M., Abate, T., Prasanna, B. M., \& Menkir, A. (2014). Managing vulnerability to drought and enhancing livelihood resilience in sub-Saharan Africa: Technological, Institutional and Policy Options. Weather and Climate Extremes, 3, 67-79. https://doi.org/10.1016/j.wace.2014.04.004

Smith, P., Gregory, P. J., van Vuuren, D., Obersteiner, M., Havlãk, P., Rounsevell, M., ... Bellarby, J. (2010). Competition for land. Philosophical Transactions of the Royal Society B: Biological Sciences, 365, 1554, 2941-2957. https://doi.org/10.1098/rstb.2010.0127

Smith, A. (1976). The Wealth of Nations. Chicago: University of Chicago Press.

UNFCCC (United Nations Framework Convention on Climate Change). (2007). Climate Change: Impacts, Vulnerabilities and Adaptations in Developing Countries. Least Developed Countries under the UNFCCC.

Valin, H., Havlík, P., Mosnier, A., \& Obersteiner M. (2010). Climate change mitigation and future food consumption patterns. Paper prepared for presentation at the $1^{\text {st }}$ Joint EAAE/AAEA Seminar, "The Economics of Food, Food Choice and Health", Freising, Germany.

World Bank. (2010). World Development Report: Development and Climate Change. The International Bank for Reconstruction and Development/The World Bank, Washington, DC. 


\section{Copyrights}

Copyright for this article is retained by the author(s), with first publication rights granted to the journal.

This is an open-access article distributed under the terms and conditions of the Creative Commons Attribution license (http://creativecommons.org/licenses/by/4.0/). 